LETTERS TO THE EDITOR

\section{Wasting as predictor of survival} in CF

Sharma and colleagues report the survival of 584 patients with cystic fibrosis (CF) attending the Royal Brompton Hospital between 1985 and 1996. ${ }^{1}$ They report that body wasting, as represented by \% ideal weight, was a significant predictor of survival before and after correction for age, sex, \% predicted $\mathrm{FEV}_{1}, \mathrm{PaO}_{2}$, and $\mathrm{PaCO}_{2}$.

In 1997 Hayllar and colleagues reported the survival of 503 patients with $\mathrm{CF}$ attending the Royal Brompton Hospital between 1969 and 1993. ${ }^{2}$ They found that low blood haemoglobin concentration $(\mathrm{Hb})$, low plasma albumin concentration, and short stature were significant predictors of survival although, of these, only height was included in their final predictive model. Other recent reports have shown both weight and height to be significant predictors of survival in $\mathrm{CF}^{3}{ }^{3}$

We recently reported the survival of 181 children with CF referred to the paediatric lung transplantation programme at Grea Ormond Street Hospital for Children (GOSH). ${ }^{5}$ Following Hayllar's report, we opted to study a wide range of variables including $\mathrm{Hb}$, albumin, and \% ideal weight as markers of nutritional status. All three variables were correlated in our population, but $\mathrm{Hb}$ and albumin were clearly better predictors of survival than \% ideal weight, both before and after correction for age, sex, resting (age corrected) heart rate, and markers of lung function and exercise tolerance. Hayllar and colleagues speculated that failure of statural growth probably reflects a degree of malnutrition. This may explain our findings, as stunting of growth could result in \% ideal weight giving an underestimate of malnutrition.

Given the previous report from their centre, it is regrettable that Sharma and colleagues did not include albumin, $\mathrm{Hb}$, and height in their prognostic modelling as they may have discovered a more complex picture. They conclude that \% ideal weight should be considered an independent risk factor for prognosis in CF. We welcome and support their conclusion, but suggest that poor nutritional status in general should be considered a risk factor and that a patient with anaemia, hypoalbuminaemia, and/or growth failure should be considered at risk, even if they are not wasted.

If you have a burning desire to respond to a paper published in Thorax, why not make use of our "rapid response" option?

log on to our website (www.thoraxjnl.com), find the paper that interests you, and send your response via email by clicking on the "eletters" option in the box at the top right hand corner.

Providing it isn't libellous or obscene, it will be posted within seven days. You can retrieve it by clicking on "read eletters" on our homepage.

The editors will decide as before whether to also publish it in a future paper issue.
On a separate point, we were unable to include $\mathrm{PaO}_{2}$ and $\mathrm{PaCO}_{2}$ in our survival analyses. In common with many paediatric centres, GOSH does not routinely perform arterial blood gas analysis in children, even in those referred for transplantation assessment. Although the value of these measures is accepted in adult patients, data from children are scanty and paediatricians are reluctant to subject children to arterial blood sampling unless the results are clearly of value. Sharma and colleagues appear to have studied these data in a large number of children, and we ask that they present the paediatric data as a subset. In particular, in how many children were arterial blood gas analyses performed, what were the $\mathrm{PaO}_{2}$ and $\mathrm{PaCO}_{2}$ values obtained, and did these results provide predictive information that was additive to that obtained less invasively? We encourage the authors to publish these data as they could change practice in other centres.

The extensive literature in this area indicates that numerous variables can be considered predictors of survival in CF. We suggest that any assessment of prognosis should include spirometric measurements, blood gas analysis in adults, and assessments of nutritional status, exercise tolerance, rate of decline, and possibly some measurement of resting energy expenditure or metabolic rate. Furthermore, in children at least, it appears that young age and female sex result in a poorer prognosis. Basing prognosis upon $\mathrm{FEV}_{1}$ and \% ideal weight alone is unlikely to be sufficient.

Portex Anaesthesia, Intensive Therapy and Respiratory Medicine Unit, Institute of Child Health, London WCIN 1EH, UK

A Wade

Epidemiology and Public Health Unit, Institute of Child Health, London WCIN IEH, UK

\section{References}

1 Sharma R, Florea VG, Bolger AP, et al Wasting as an independent predictor of mortality in patients with cystic fibrosis. Thorax 2001;56:746-50.

2 Hayllar KM, Williams SG, Wise AE, et al. A prognostic model for the prediction of survival in cystic fibrosis. Thorax 1997;52:313-7.

3 Beker LT, Russek-Cohen E, Fink RJ. Stature as a prognostic factor in cystic fibrosis survival. $J$ Am Diet Assoc 2001;101:438-42.

4 Liou TG, Adler FR, Fitzsimmons SC et al. Predictive 5-year survivorship model of cystic fibrosis. Am J Epidemiol 2001;153:345-52.

5 Aurora $\mathbf{P}$, Wade A, Whitmore $\mathrm{P}$, et al. A model for predicting life expectancy of children with cystic fibrosis. Eur Respir J 2000; 16:1056-60.

\section{Authors' reply}

We welcome the response of Drs Aurora and Wade to our article on the prognostic value of wasting in patients with cystic fibrosis (CF). ${ }^{1}$ They suggest that poor nutritional status in general should be considered a risk factor for mortality with particular emphasis on anaemia and hypoalbuminaemia. While we accept that nutritional status is likely to relate strongly to mortality in CF, we disagree that haemoglobin and albumin should be considered more accurate markers of prognosis than
$\%$ ideal weight. There have been relatively few studies evaluating the prognostic value of haemoglobin and albumin in CF, none of which have shown these variables to be independent predictors of mortality. ${ }^{23}$ Furthermore, we note that in the study by Aurora and colleagues on 181 children with severe CF, neither haemoglobin nor albumin were found to be significant prognostic markers in multivariate survival analysis (table 3 ). ${ }^{2}$

In our paper we demonstrate that, in a stable outpatient CF population, \% ideal weight represents an accurate predictor of survival which is independent of other established prognostic markers such as lung function and arterial blood gas tensions. The addition of \% predicted $\mathrm{FEV}_{1}$ to \% ideal weight provides an even stronger model with which to predict survival. We do not propose that these two variables should be the only ones considered when evaluating patients, but that they represent simple and accurate prognostic parameters which can be easily assessed in the outpatient clinic.

With regard to blood gas analysis, in our study this was performed in 58 children (age $<18$ years). We found the arterial oxygen tension but not carbon dioxide tension to be a significant predictor of survival in this age group (unpublished data). Furthermore, \% ideal weight continued to be a strong and independent predictor of survival in children as well as in adults with CF.

RS is supported by the Robert Luff Foundation. SDA has been supported by the Ernst- and Bertha Grimmke Stiftung, Düsseldorf, Germany. SDA is holding a postgraduate fellowship of the Max-DelbrückCentrum for Molecular Medicine, Germany.

M E Hodson

Department of Cystic Fibrosis, Royal Brompton Hospital and Harefield NHS Trust, London SW3 6LY, UK; r.sharma@ic.ac.uk

R Sharma

Clinical Cardiology, National Heart, Lung Institute, Imperial College School of Medicine, London, UK

S D Anker

Clinical Cardiology, National Heart \& Lung Institute, Imperial College School of Medicine, London, UK and Franz-Volhard-Klinik (Charite, Campus Berlin-Buch), Max-Delbrück-Centrum for Molecular Medicine, Berlin, Germany

\section{References}

1 Sharma R, Florea VG, Bolger AP, et al. Wasting as an independent predictor of mortality in patients with cystic fibrosis. Thorax 2001;56:746-50.

2 Aurora P, Wade A, Whitmore P, et al. A model for predicting life expectancy of children with cystic fibrosis. Eur Respir 2000; 16:1056-60

3 Hayllar KM, Williams SG, Wise AE, et al. A prognostic model for the prediction of survival in cystic fibrosis. Thorax 1997;52:313-7.

\section{Pulmonary rehabilitation}

In their paper the members of the BTS Standards of Care Subcommittee on Pulmonary Rehabilitation provide a clear statement on the current status of pulmonary rehabilitation in the UK. ${ }^{1}$ Funding for pulmonary rehabilitation has lagged behind cardiac rehabilitation even though the evidence base is stronger and patients are usually more disabled. Let us 
hope that the government, which places so much weight on evidence based medicine, will agree with your statement that there are now strong arguments for widespread development of pulmonary rehabilitation services.

The key consideration for new services is accessibility. In this, location and frequency of attendance may be critical. Local community based services have the advantage over hospital programmes in being closer to the patients, reducing time and costs for transport. They may be better placed for providing ongoing support after the programme has finished, both in terms of social contact between the group and follow up programmes. It is not easy to demonstrate whether these factors are important in practice, but our patients tell us that they strongly influence both recruitment and drop out rate. Simple things like parking at hospitals may prove insuperable obstacles to patients with severe COPD.

On the surface it would seem that the more often the rehabilitation is performed, the more likely there is to be a positive outcome. Based on hospital programmes, the committee states that "at least three exercise sessions per week are necessary for sustained improvement, two of which should be supervised". Reducing the number of sessions in the programme may make it more accessible, especially when it is difficult to attend either through morbidity, social factors, or being at work. Home based programmes with minimal supervised exercise showed good outcomes in the Netherlands. ${ }^{2}$ Our own group has been running a once weekly programme, initially in general practice ${ }^{3}$ and now based in the community. Over 50 patients have enrolled so far, and the shuttle test and health status scores show good clinically important gains.

Reducing the frequency of the programme may also have some resource and cost advantages. ${ }^{4}$ Even when money is found, staff-especially physiotherapists - may be in short supply. Once weekly programmes may be more feasible and appropriate for the community; they should not be discouraged until more results are published.

As small community based programmes proliferate with both non-specialist rehabilitation teams and different schemes, the quality of the service must be assessed. The guidelines should make a clear statement as to the most practical and important outcome measures to be recorded. Only with common yardsticks can the different interventions be compared and standards maintained. R Jones
Respiratory Research Unit, Department of Primary
Health Care \& General Practice, Plymouth
Postgraduate Medical School, Plymouth PL6 8BX,

\section{References}

1 BTS Standards of Care Subcommittee on Pulmonary Rehabilitation. Pulmonary rehabilitation. Thorax 2001;56:827-34.

2 Wijkstra PJ, Strijbos JH. Home-based rehabilitation for patients with chronic obstructive pulmonary disease. Monaldi Arch Chest Dis 1998;53:450-3.

3 Jones RCM, Copper S, Dobbs F. A pilot study of short pulmonary rehabilitation in general practice. Thorax 1999;54(Suppl 3):62.

4 Jones RCM, Copper S, Riley O, et al. Short pulmonary rehabilitation in primary care: a cheaper option? Eur Respir J 2000;16(Suppl 31): 159 .

\section{Author's reply}

On behalf of the BTS Standards of Care Subcommittee on Pulmonary Rehabilitation we thank Dr Jones for his supportive comments. We would obviously agree that provision for pulmonary rehabilitation has fallen behind that for patients with similar disability from cardiac disease. One of the purposes of the BTS statement is to provide support for the argument for greater resources. We would also agree with Dr Jones that accessibility for rehabilitation is a key component for success and must ultimately take place in a community setting to cater for the potentially large numbers of disabled patients. However, as rehabilitation moves into the community, it will be very important to maintain standards and monitor outcomes to ensure that the process remains effective.

It is encouraging that pilot projects have now begun in the community and we look forward to seeing high grade evidence which can be incorporated in future BTS statements. At present the effectiveness of home based and low session frequency rehabilitation is uncertain. The original Dutch experience quoted by Dr Jones is a little ambiguous. ${ }^{1-3}$ When the original papers are read carefully, it is clear that two supervised exercise sessions per week are conducted within the physiotherapist's home rather than the patient's own home. In fact, other attempts at genuine home based rehabilitation in patients with severe COPD have not been so successful. ${ }^{4}$ At present also there is inadequate evidence to support the effectiveness of once weekly supervised exercise programmes. ${ }^{5}$ One further difficulty associated with poor service provision is that many research projects are conducted from a background of clinical inexperience because of the necessity to obtain research funding to start a programme!

Finally, we would support Dr Jones in his plea for standardisation of process and outcomes. We believe that the BTS statement did give a clear indication as to what outcomes of functional performance and health status might be sensitive and appropriate. The British Thoracic Society and the British Lung Foundation have plans to set up a register of rehabilitation programmes in the UK to assist with this process.

M D L Morgan

Institute for Lung Health, Department of Respiratory Medicine, Glenfield General Hospital, Leicester LE3 9QP, UK; mike.morgan@uhl-tr.nhs.uk

\section{References}

1 Strijbos JH, Postma DS, van Altena R, et al. Feasibility and effects of a home-care rehabilitation program in patients with chronic obstructive pulmonary disease. J Cardiopulm Rehabil 1996; 16:386-93.

2 Strijbos JH, Postma DS, van Altena R, et al. A comparison between an outpatient hospital-based pulmonary rehabilitation program and a home-care pulmonary rehabilitation program in patients with COPD. A follow-up of 18 months. Chest 1996;109:366-72.

3 Wijkstra PJ, Strijbos JH. Home-based rehabilitation for patients with chronic obstructive pulmonary disease. Monaldi Arch Chest Dis 1998;53:450-3.

4 Wedzicha JA, Bestall JC, Garrod R, et al. Randomized controlled trial of pulmonary rehabilitation in severe chronic obstructive pulmonary disease patients, stratified with the MRC dyspnoea scale. Eur Respir J 1998; 12:363-9.

5 Puente-Maestu L, Sanz ML, Sanz P, et al. Comparison of effects of supervised versus self-monitored training programmes in patients with chronic obstructive pulmonary disease. Eur Respir J 2000;15:517-25.

\section{Respiratory disease and proximity to coke works}

With reference to the paper by Aylin et al published in the March 2001 issue of Thorax, we would like to raise the following points.

Previous studies have concentrated on acute ill health due to particulate emissions but chronic effects have been neglected. This paper aimed to address this issue, with consideration being given to "at risk" groups. However, only acute events requiring hospital admission were included, with no consideration being given to those patients in the community with established cardiorespiratory disease. All studies have limitations but these should not be so significant as to invalidate the outcome. The authors recognised many of their limitations, such as socioeconomic factors and hospital variation, but others such as occupational exposure of the older population and emission differences between the sites and their surrounding industries were not considered. In addition, the authors failed to address major limitations from previous studies so the opportunities presented by such a large study were wasted because previous mistakes were repeated. Overall, these influences are so significant that any outcome cannot be considered valid, and hence no conclusions can be drawn.

We suggest that any follow up studies should take advantage of the effective population criteria used in this study and should include a more concise explanation of study design, time scale, statistical protocol, and emission data.

K Amos, M Carson, S Goodfellow, P Homan, G Phull Stage 3 medical students Department of Epidemiology and Public Health, University of Newcastle upon Tyne, Newcastle upon Tyne NE2 4HH, UK

\section{References}

1 Aylin P, Bottle A, Wakefield J, et al. Proximity to coke works and hospital admissions for respiratory and cardiovascular disease in England and Wales. Thorax

$2001 ; 56: 228-33$.

\section{Embolisation in Behçet's disease}

I read with interest the excellent review of Behçet's disease by Erkan et al and wish to comment on the treatment of pulmonary artery aneurysms (PAA) with embolisation. Durieux et al reported the first case in 1981, and a further four successfully treated cases have been reported since 1985..$^{2-5}$

As reported by others, ${ }^{6-8}$ we have found that surgical treatment of PAA in Behçet's disease is associated with a high rate of mortality so we have started to use embolisation as the first line of treatment for massive haemoptysis in patients with Behçet's disease. Our first patient underwent embolisation of an aneurysm involving the right middle and lower lobe arteries in January 2000, and a second patient with an aneurysm in the right upper lobe was embolised in October 2000. Both are alive with no apparent haemoptysis and serial control scans show no aneurysm formation. We also had a patient with an aneurysm of unknown aetiology involving the entire pulmonary arterial tree starting from the mean pulmonary artery and extending bilaterally towards the lobar branches. Pulmonary angiography did not reveal leakage and embolisation was not attempted as it was impossible to block the huge aneurysm. He 
died a week later despite high doses of corticosteroid and azathioprine.

In Behçet's disease PAA are usually multiple and have a tendency to recur. Immunosuppressants should be the first line treatment as regression is possible. Life threatening massive haemoptysis necessitates intervention. Surgical treatment mostly consists of major anatomical resection rather than preserving lung tissue. Embolisation can be performed in most cases and any recurrence may be re-embolised. Pulmonary infarction has not been observed so far, although it is a possibility. Thrombosis of the great veins is a well known problem and surgery should be preferred for life threatening haemoptysis if endovascular access is not available.

A K Bozkurt Department of Thoracic and Cardiovascular Surgery, University of Istanbul, Cerrahpasa Medical Faculty, Istanbul, Turkey; akbozkurt@yahoo.com

\section{References}

1 Erkan F, Gül A, Tasali E. Pulmonary manifestations of Behcet's disease. Thorax 2001;56:572-8.

2 Durieux $P$, Bletry $O$, Huchon G, et al. Multiple pulmonary arterial aneurysms in Behcet's disease and Hughes-Stovin syndrome. Am J Med 1981;71:736-41.

3 Lacombe $\mathbf{P}$, Frija G, Parlier $\mathrm{H}$, et al. Transcatheter embolization of multiple pulmonary artery aneurysms in Behcet's syndrome. Report of a case. Acta Radiol Diagn (Stockh) 1985;26:251-3.

4 Mouas $\mathrm{H}$, Lortholary $\mathrm{O}$, Lacombe $\mathrm{P}$, et al. Embolization of multiple pulmonary arterial aneurysms in Behcet's disease. Scand J Rheumatol 1996;25:58-60.

5 Lacombe P, Qanadli SD, Jondeau G, et al Treatment of hemoptysis in Behcet syndrome with pulmonary and bronchial embolization. $J$ Vasc Intervent Radiol 1997;8:1043-7.

6 Tuzun H, Hamuryudan V, Yıldırım S, et al. Surgical therapy of pulmonary arterial aneurysms in Behçet's syndrome. Ann Thorac Surg 1996;61:733-5

7 Sayin AG, Vural FS, Bozkurt AK, et al. Right atrial thrombus mimicking myxoma and bilateral pulmonary artery aneurysms in a patient with Behcet's disease: a case report. Angiology 1993;44:915-8.

8 de Montpreville VT, Macchiarini P, Dartevelle PG, et al. Large bilateral pulmonary artery aneurysms in Behcet's disease: rupture of the contralateral lesion after aneurysmorrhaphy. Respiration 1996;63:49-51.

\section{BOOK REVIEWS}

\section{Non-Invasive Respiratory Support}

A K Simonds. Edward Arnold, 2001, £29.99, pp 304. ISBN 0340762594

The second edition of Dr Simonds' book gives a comprehensive up to date review of the rapidly expanding field of non-invasive respiratory support. The material covers acute and chronic applications of non-invasive ventilation (NIV), giving an overview of NIV in these settings followed by discussions on specific disease applications. Chapters cover topics such as paediatric NIV, CPAP, medicolegal implications and physiotherapy, nursing, and other treatment during NIV. This book will be of use to all those wishing to practise an evidence-based service, and the evidence is clearly presented and well argued. In line with the significant focus on the practical aspects of running a service, the book deals well with the more widespread issues involved in using NIV.

I particularly liked the practical slant to much of the book, especially the focus on problem solving and application in the acute setting or during procedures. Many colleagues, like myself, will find the answers to most of their (and their patients') questions here. Having had some insight into the problems involved in setting up an NIV service, I would expect physicians establishing a service to find the initial chapters-detailing equipment, service requirements, and cost implications-informative and constructive.

This readable book gives an excellent overview of the subject, is well referenced, and supported with good illustrations. I would highly recommend it as a basic reference and a practical guide for all respiratory trainees and physicians using an NIV service.

L Turner

\section{Practical Paediatric Respiratory} Medicine

Edited by $M$ Silverman, C L O'Callaghan. London: Arnold, 2001, £39.50, pp 293 (paperback). ISBN 0340741260

It is always pleasing when a new publication devoted to respiratory disease in childhood is published. This text appears to be aimed at children's respiratory nurses and paediatric trainees, providing a grounding in many facets of paediatric respiratory medicine. The book does not aim to be comprehensive but rather aims to be an aid to those during training. The authors, largely drawn from Leicester, bring their practical as well as their theoretical expertise with a view to producing a pragmatic text that will support those faced with children in a variety of settings. Perhaps the most valuable aspect of this book are the case studies included in each chapter. These are a useful and instructive means of bringing the information within the text to life and highlighting "real" life management issues.

While, in the main, chapters start from the basics and provide a good introduction to those with relatively little experience, a number of chapters go beyond clinical practice into more theoretical areas, reflecting the author's particular interest.

The book will be a useful addition to the library shelves, complementing existing paediatric respiratory texts.

M Everard 